\title{
Study and Realization of a System to Reduce the Effect of the Instantaneous Rotation Center (IRC) in an Electric Vehicle
}

\author{
Hemza SAIDI $^{* 1}$, Boualem DJEBRI ${ }^{2}$, Rachid TALEB ${ }^{3}$ \\ ${ }^{1}$ Electrical Engineering Department, Mohamed Boudiaf University of Science and Technology, Oran, Algeria \\ ${ }^{2}$ Electrical Engineering Department, Hassiba Benbouali University, LGEER Laboratory, Chlef, Algeria \\ ${ }^{3}$ Polytechnic School of Architecture and Town Planning, City Laboratory, El Harrach, Algiers, Algeria \\ *hamzaing2008@yahoo.fr
}

\begin{abstract}
The problem of the stability of electric vehicles is difficult during their displacements, then more and more difficult when the (EV) has a several driving wheels, and its way has a curved trajectory, this problem causes a danger for the (EV), the effect of the instantaneous center of rotation (ICR), every year many deaths in the world because of the accidents causing by this problem mentioned before. The desire to have more safety in this type of vehicle encourages us to develop driving assistance systems that help to control the (EV) on the road. Indeed, our objective of this work is to realize a system to reduce the effects of (ICR) with two wheels drive (EV) by realizing an intelligent system implemented on ardouino, and a Labview interface which used for data processing. The intelligent system controls the electric motors (DC motor), which is placed inside the wheels with other equipments allows us to visualize the speed's variations of the motors which we have already. All this is a guarantee by a new management control algorithm.
\end{abstract}

Keyword - Electric vehicle, ICR, Control, DC motor

\section{INTRODUCTION}

The instantaneous axis of rotation is a term used in classical mechanics and more particularly in kinematics in order to designate the axis around which a solid is rotating at a given instant with respect to a reference frame. If we can use the simplification of plane problems, we talk about instantaneous center of rotation (ICR).

When a solid isolated in the mechanical sense of the term moves according a trajectory in a plane, the ICR is defined as the point where the velocity vector is zero. The ICR lies on the perpendicular to each velocity vector of the isolated solid passing through the point of application of the latter. When the isolated solid moves only in translation in a plane, the ICR is projected to the infinity.

Let us consider a plane motion which is not a movement of translation. During for a short period, all happen as if the solid was rotating around its ICR. We can then apply the relations established in the case of rotational movements, and in particular the notion of a triangle of velocities. This allow to determine the velocity vector at any point of the solid, provided that we know:

- The velocity vector at a point;

- The position of the ICR.

\section{MOVEMENT IN LACE TO A LOW-SPEED}

According to the Ackermann model illustrated in Figure 1, the steering's angles of the front train are given by:

$$
\begin{aligned}
& \operatorname{Tan} \beta d=L /(h-h / 2) \\
& \operatorname{Tan} \beta g=L /(R+h / 2)
\end{aligned}
$$

Then:

$$
\cot \beta g-\cot \beta d=h / L
$$

With: $\beta g \leq \beta d$ 


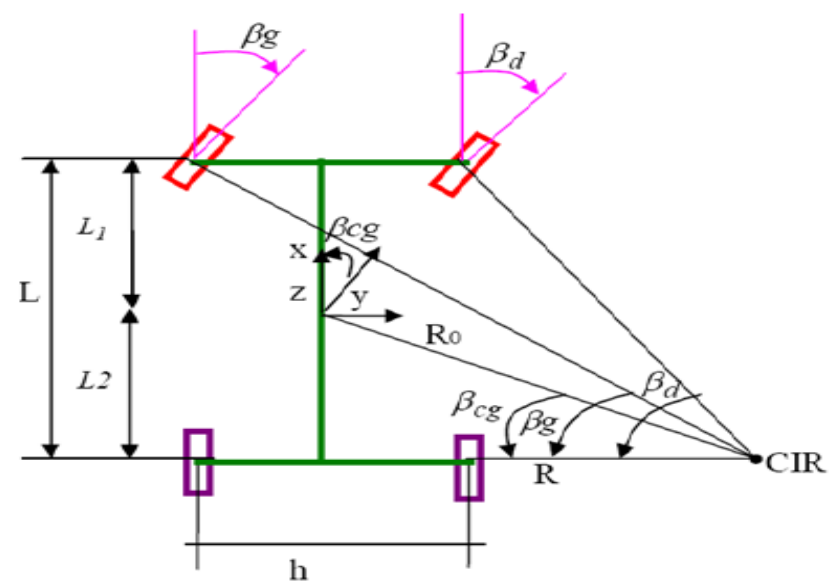

Fig. 1. The Ackerman lace model

On the other hand, the bicycle model illustrated in Figure 2 gives:

The steering's angle of the front train

Tan $\beta b=L / R$

Then:

$$
\operatorname{Cot} \beta b=(\cot \beta g+\cot \beta d) / 2=R / L
$$

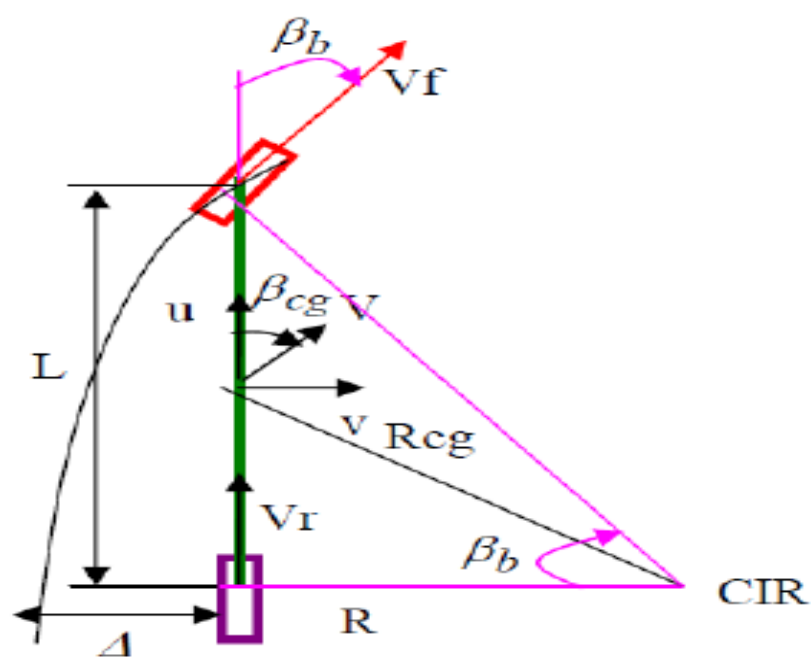

Fig. 2. Ackerman bicycle model

Center of mass curvature's ray

$$
\begin{aligned}
& R c g=\sqrt{L_{2}^{2}+R^{2}}=\sqrt{L 22}+L^{2} \cot ^{2} \beta b \\
& R c g=R \sqrt{1+L_{2}^{2} / R^{2}} \approx\left(1+L_{2}^{2} R 2\right) \approx R
\end{aligned}
$$

Relationship between the curvature and the steering angle $R c g \approx R \approx L \cot \beta b \approx L \beta b$ with:

$$
\cot \beta b=R / L
$$

Then we will have: $\mathrm{B} b=L / R$

Divert of the mass's center

$$
\begin{aligned}
& \beta c g=\arctan \left(\frac{L 2}{R}\right) \beta c g=\arcsin \left(\frac{L 2}{R}\right) \\
& =\arcsin \left(L 2 \sqrt{R 2}+L_{2}^{2}\right)=L 2 / L \beta b \\
& \beta c g=L 2 / L \beta b
\end{aligned}
$$

The displacement of the trajectory of the back train

$$
\begin{aligned}
& R f=\sqrt{ } R 2+L^{2} \\
& \Delta=R f-R=\left(\sqrt{1}+L^{2} / R^{2} /-1\right)
\end{aligned}
$$


We have that: $\sqrt{ } 1+x 2 \approx 1+x / 2+\ldots \ldots$

$\Delta=L^{2} / 2 R$

With:

$\mathrm{B} d$ : Steering angle of the front right wheel.

$\mathrm{B} g$ : Steering angle of the front left wheel.

$\mathrm{B} b$ : Steering angle in bicycle mode.

L: Length of vehicle wheelbase.

R: IRC ray of the back train.

$R f$ : Ray of IRC plus The displacement of the back train.

$\mathrm{H}$ : Vehicle length

$R c g$ : Ray of curvature of the mass'es center

L1: Front half-wheelbase.

L2: Back half-wheelbase.

$\mathrm{B} c g$ : Steering angle of the mass'es center of the vehicle.

$\Delta$ : The the trajectory's split of the back train.

\section{III.HIGH-SPEED IN LACE MOVEMENT}

The study of a movement of the vehicle in lace at high speed amount leads us to study the rotation in lace under steady state with the hypothesis to take into account the angle of drift of the front and back train. Fig 3 illustrates the lace movement of a high speed bicycle model.

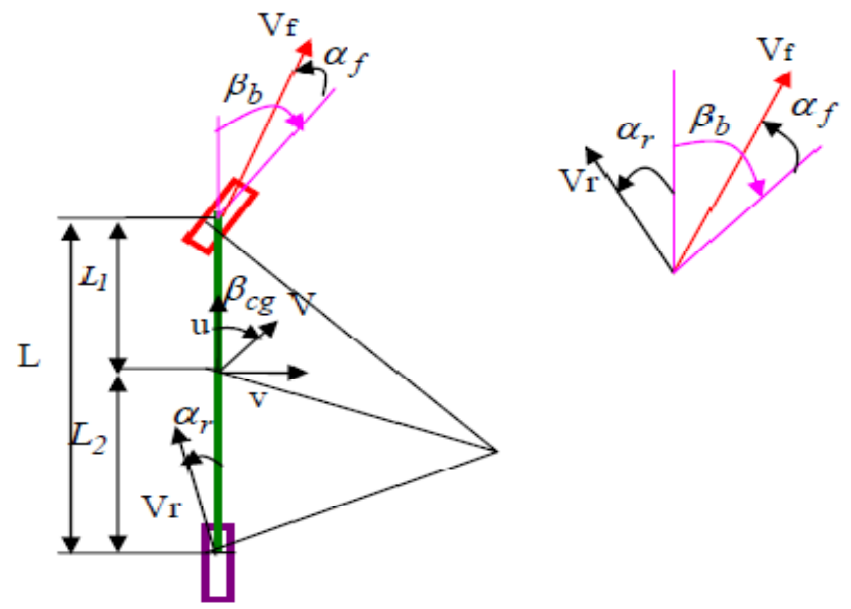

Fig. 3. Representation of the high-speed bicycle model

From Fig. 3 we can deduce:

Steering angle as a function of drift angle:

$$
B b=L / R+\alpha f-\alpha r
$$

Equations of behavior of the tire:

$$
F y f=C \alpha f \alpha f F y r=C \alpha r \alpha r
$$




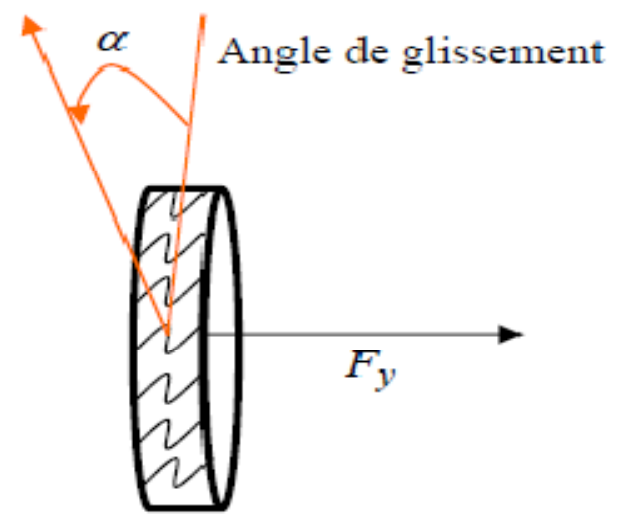

Fig. 4. Behavior of the tire

Equations of lateral equilibrium and rotation:

$$
\begin{aligned}
& F y f \cos \beta b+F y r=m V 2 / R \\
& F y f \cos \beta b b+F y r L 2=0
\end{aligned}
$$

By small angle hypothesis:

$$
\begin{aligned}
& \text { Fyf }=(L 2 / L) m(V 2 / R) \\
& \text { Fyr }=(\mathrm{L} 1 / \mathrm{L}) \mathrm{m}(\mathrm{V} 2 / \mathrm{R})
\end{aligned}
$$

Using the above equations:

$$
\begin{aligned}
& F y f=f \alpha f \alpha f=(L 2 / L) m(V 2 / R) \\
& F y r=\operatorname{r\alpha r\alpha r}=(L 1 / L) m(V 2 / R)
\end{aligned}
$$

We obtain

$$
\alpha f / \alpha r=L 2 C \alpha r / L 1 C \alpha f
$$

Steering angle according to speed and lace abrupt nesses.

$$
B b=L / R+((m L 2 / C \alpha f)-(m L 1 / C \alpha r L)) V 2 / R
$$

With:

Ar: Drift angle of the back train.

Af: Angle of drift of the front train.

Fyf: Front train lateral force.

Fyr: back train lateral force.

$m$ : Vehicle mass.

$V$ : forward speed.

$c \alpha f$ : Rigidity coefficient of the lateral force of the front train $(\mathrm{N} / \mathrm{deg})$.

car: Rigidity coefficient of the lateral force of the back train $(\mathrm{N} / \mathrm{deg})$.

$L$ : Length of vehicle wheelbase.

\section{IV.STUDY OF DC MoTOR}

It is necessary to maintain the velocity a at determined values in the presence of the external or internal perturbations influencing these quantities being inherently variable. We will realize a command of a 'Proportional-Integral ' implement at a microcontroller-based system.

For this, we will begin with a description of the various components making up our system. Obtaining his mathematical model will allow us to define the different gains of our regulator. 


\section{DESCRIPTION OF THE SYSTEM}

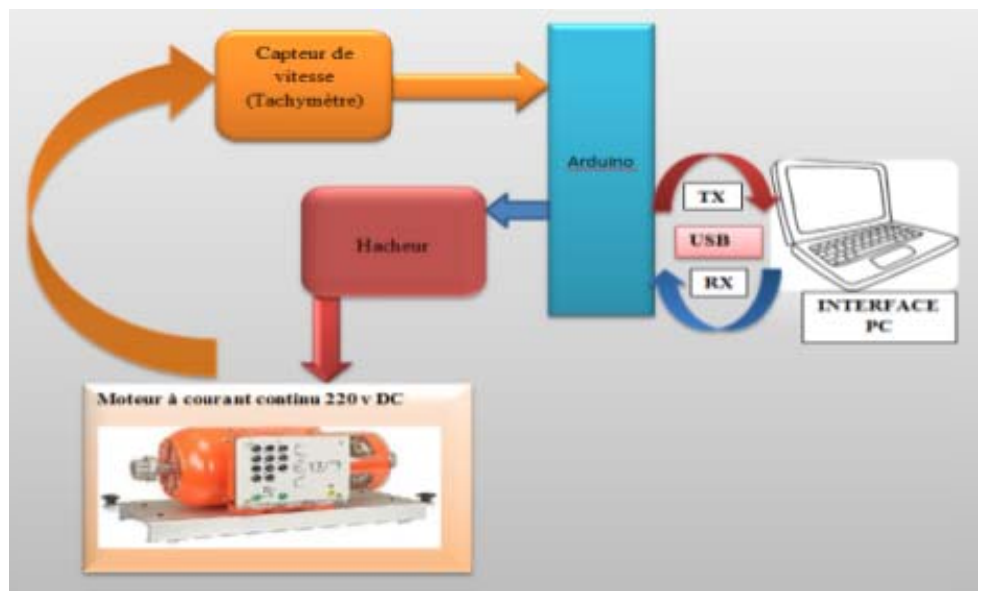

Fig. 5. Synoptic diagram of the test bench

\section{THE DC MOTOR}

This model SE-2662-5A from manufacturer NL (lucas-nuelle) Motors. This motor has an external diameter of $40 \mathrm{~mm}$, a length of $86.2 \mathrm{~mm}$, a power of $1000 \mathrm{~W}$ and a nominal supply voltage of $220 \mathrm{~V}$ DC. It can run at $2100 \mathrm{tr} / \mathrm{min}$, requires an IErr current of $0.24 \mathrm{~A}$. For the armature a nominal supply voltage of $220 \mathrm{~V} \mathrm{DC}$ and a nominal current of 6.2A. The motor is Controlled by pulse width modulation signals PMW generated by the microcontroller.

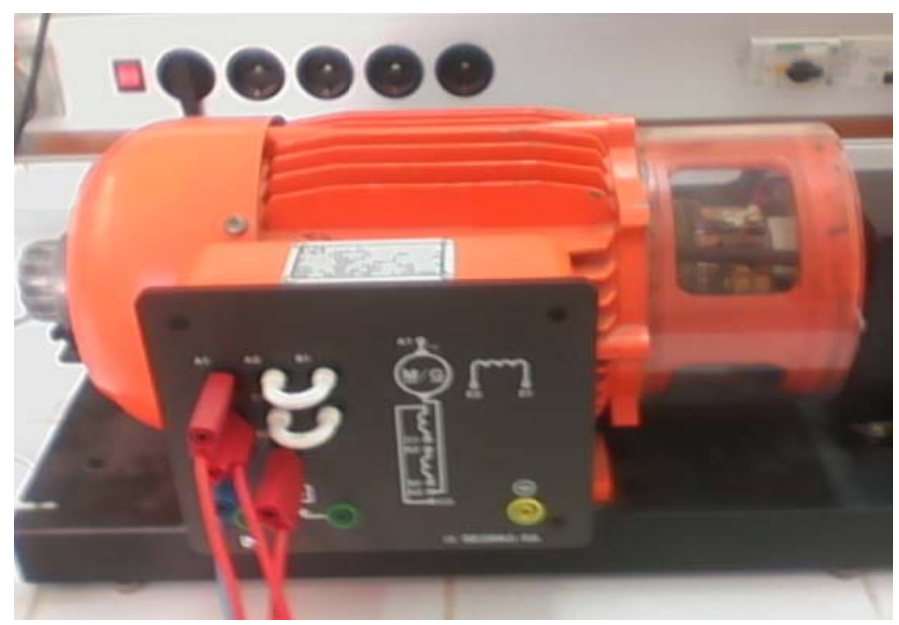

Fig. 6. The DC motor and its nameplate

VII. REPRESENTATION OF SYSTEMS IN MATHEMATICAL FORM:

To identify a real dynamic system, is to characterize an another system based on the experimental knowledge of inputs and outputs in order to obtain a behavioral identity.

There are two methods of graphic methods and statistical methods [1,2]. The main goal of this identification is to find the settings system of an input-output model.

\section{THE IDENTIFICATION SYSTEM (PRACTICAL):}

We used the Arduino card as an interface card between our system and the computer. The computer is equipped with a LabVIEW interface enabling it to acquire and store input and output samples Fig. 7 [3]. 


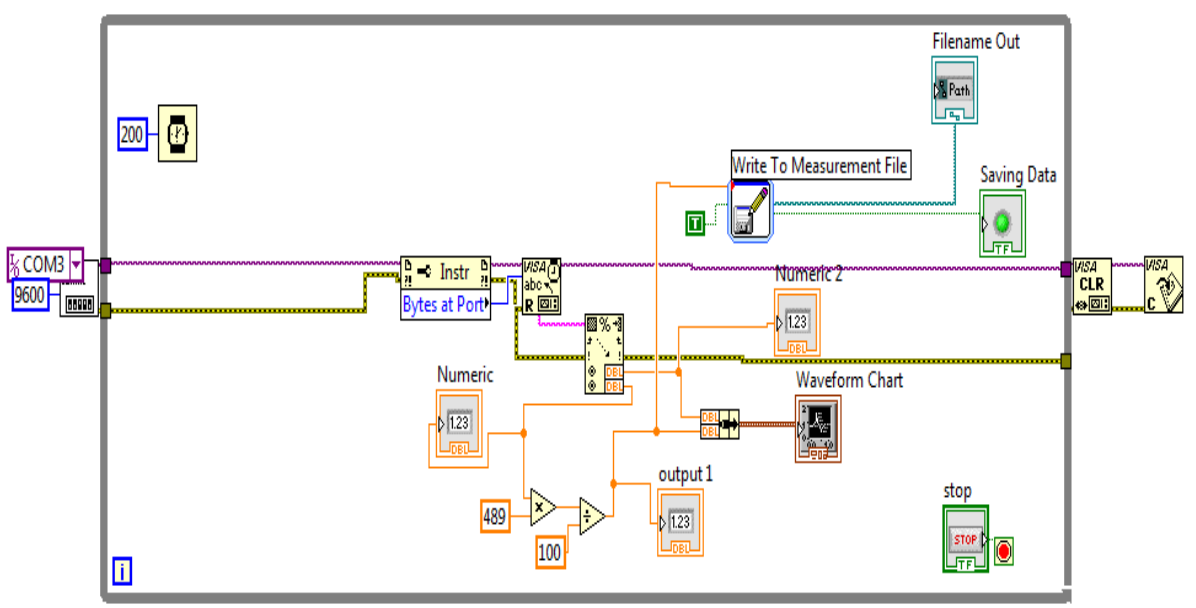

Fig. 7. Block diagram of a serial visa with the write to measure file.

The (.lvm) file is designed so that it facilitates parsing the reading when imported into a spreadsheet. Obtaining a sample file (.lvm) compatible to MATLAB- will be useful in the identification operation to find the mathematical model we are looking for using its "MATLAB identification toolbox". The following figure gives an overview on the interface of the LabVIEW (Fig. 8) and the MATLAB tool (Fig. 9) [5].

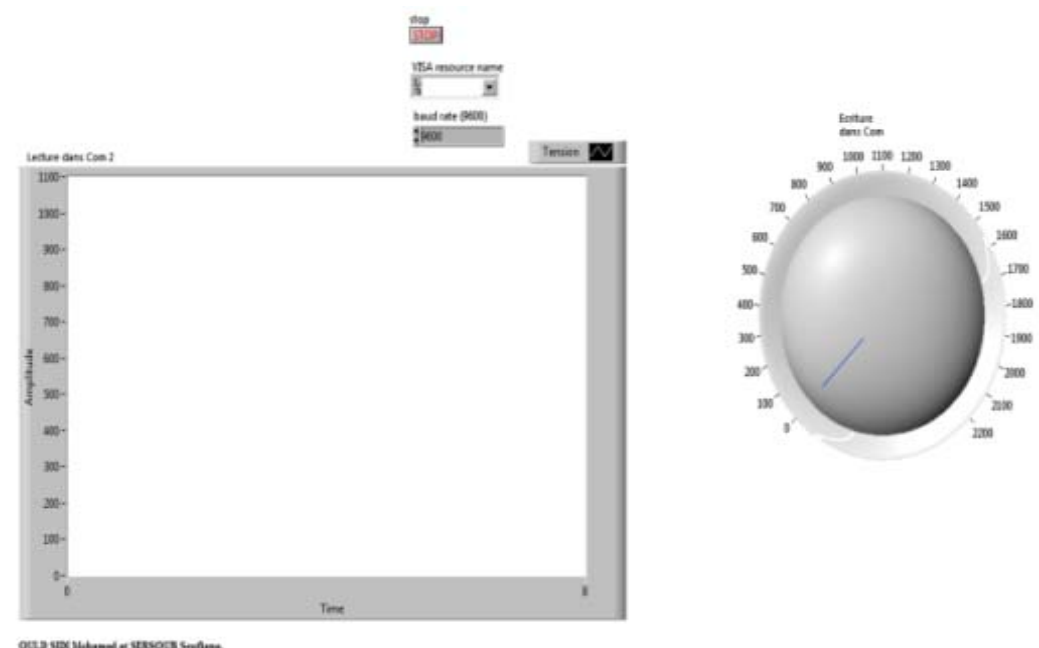

Fig. 8. Acquisition tool interface

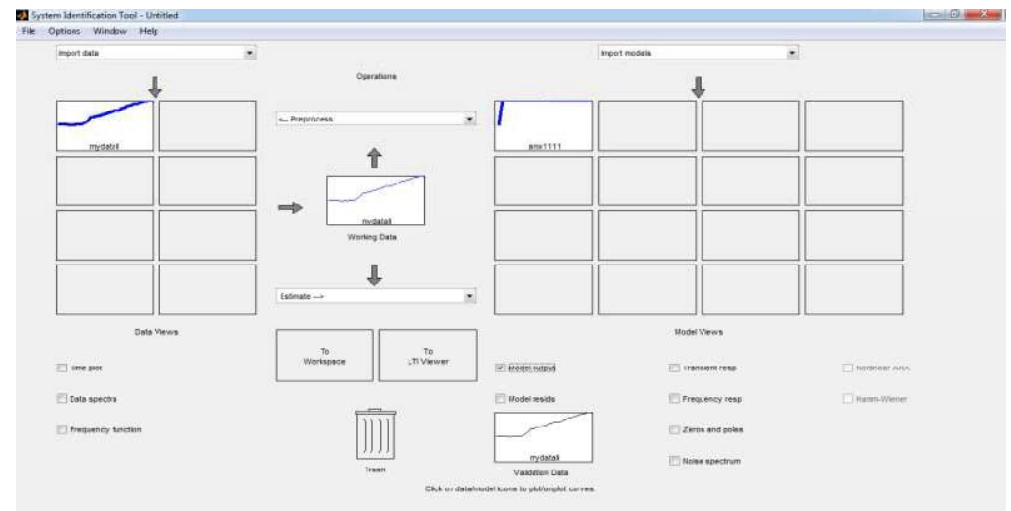

Fig. 9. "Matlab identification toolbox" tool interface. 


\section{Process identification Results:}

When we had excited the system with a step, we obtained the following answer:

$\mathrm{U}(\mathrm{k})$ : input set point. $\mathrm{Y}(\mathrm{k})$ : system response

We note that the sampling time is Ts $=0.1 \mathrm{~s}$.

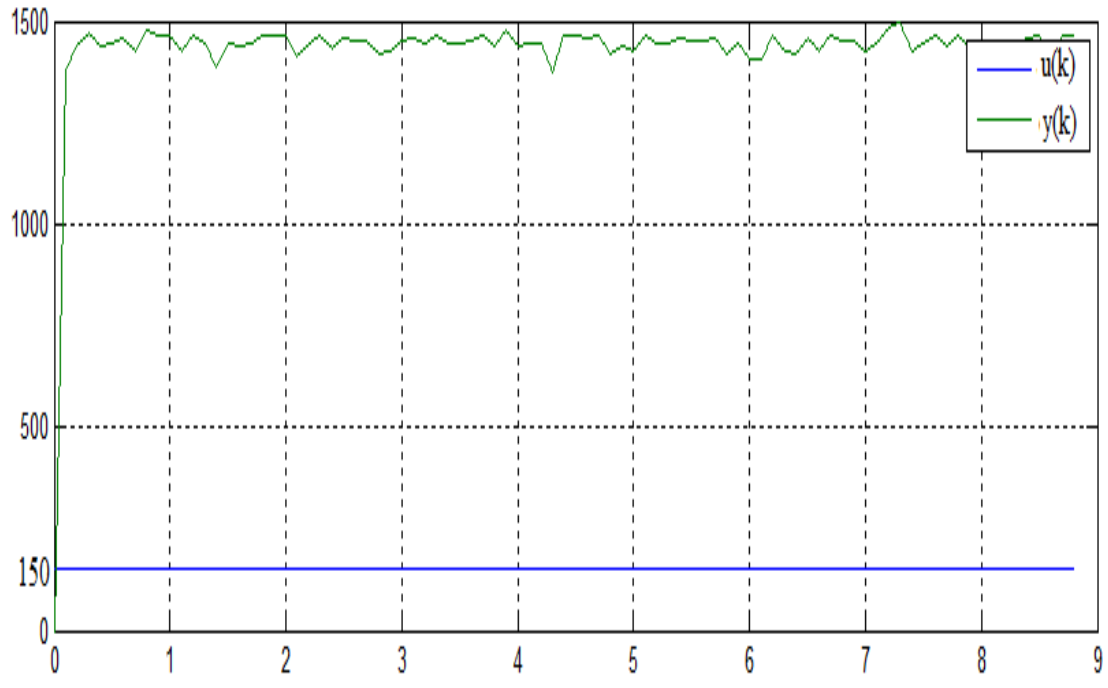

Fig. 10. Response of the system to a step

\section{ESTIMATION OF THE TRANSFER FUNCTION OF THE SYSTEM IN THE IDENTIFICATION APPLICATION}

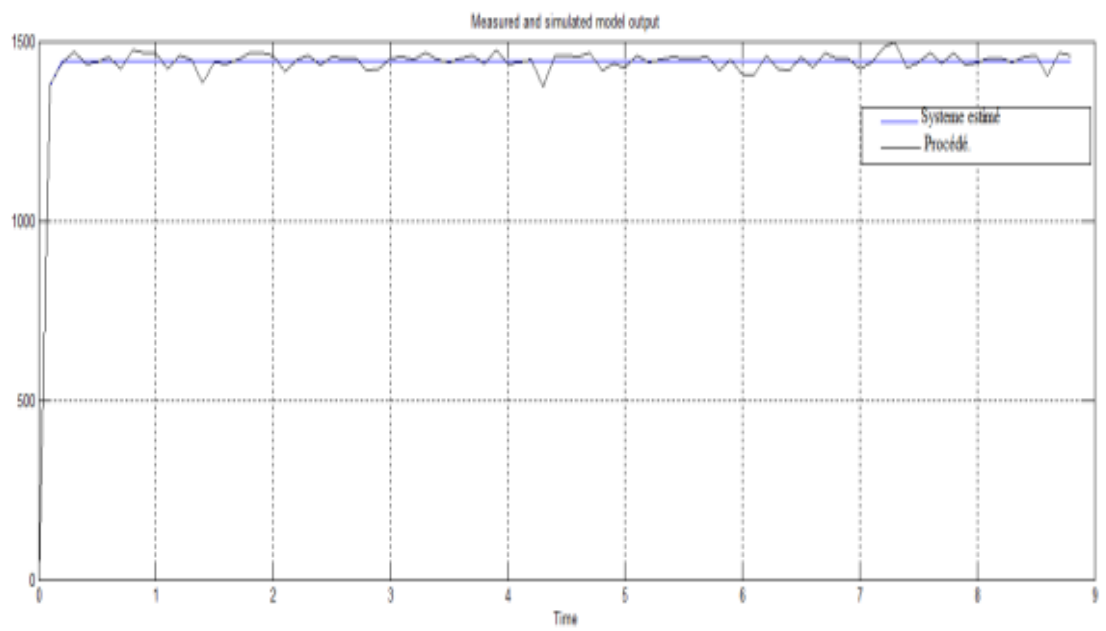

Fig. 11. The system estimated by its transfer function.

Hence the continuous transfer function of the system:

$$
G(s)=\frac{9.79}{1+0.29 S}
$$

\section{REgUlation WITH PI}

The integral corrector is generally associated with the proportional corrector, it then develops a command which can be given by the following relation:

$$
\mathrm{u}(\mathrm{t})=K_{P}\left(\varepsilon(t)+K_{i} \int_{0}^{t} \varepsilon(t) d t\right)
$$

The transfer function of the corrector is then given by:

$$
\mathrm{C}(\mathrm{p})=\frac{K_{P} S+K_{i}}{s}
$$




\section{CALCULATION OF THE CONTROLLER PARAMETERS:}

The parameters of the regulator are defined as a function of the damping $\zeta$ and the Pulsation $\omega_{n}$.

$$
\begin{aligned}
K_{i} & =\frac{\omega_{n} 2 \tau}{k} \\
K_{p} & =\frac{2 \xi \omega_{n} \tau-1}{k} \\
\omega_{n} & =\frac{5}{\xi t_{r}}
\end{aligned}
$$

\section{SimULATION:}

After calculating the parameters of the controller, we performed the simulation with Matlab/Simulink simulation software and obtained the following results (Fig. 12):

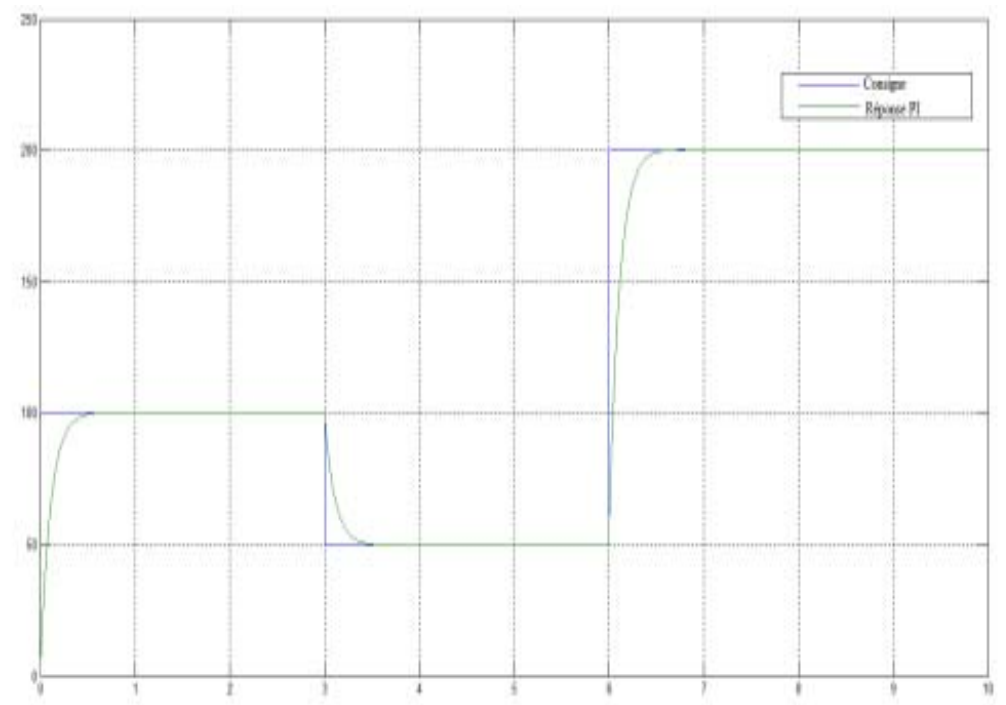

Fig. 12. Setpoint tracking and rejection of perturbations with PI (simulation)

\section{INTERPRETATION OF EXPERIMENTAL RESULTS:}

Fig.13 illustrates the behavior of our system after the implementation of the digital PI controller. At first, we gave a setpoint of $\mathrm{N}=1500 \mathrm{tr} / \mathrm{min}$, we note that the output of the system follows this instruction. Then we came down to $\mathrm{N}=500 \mathrm{tr} / \mathrm{min}$, we also notice that the output of the system follows. Finally, with $\mathrm{N}=1000 \mathrm{tr} / \mathrm{min}$, the same desired behavior was obtained. The PI regulator has given satisfactory results.

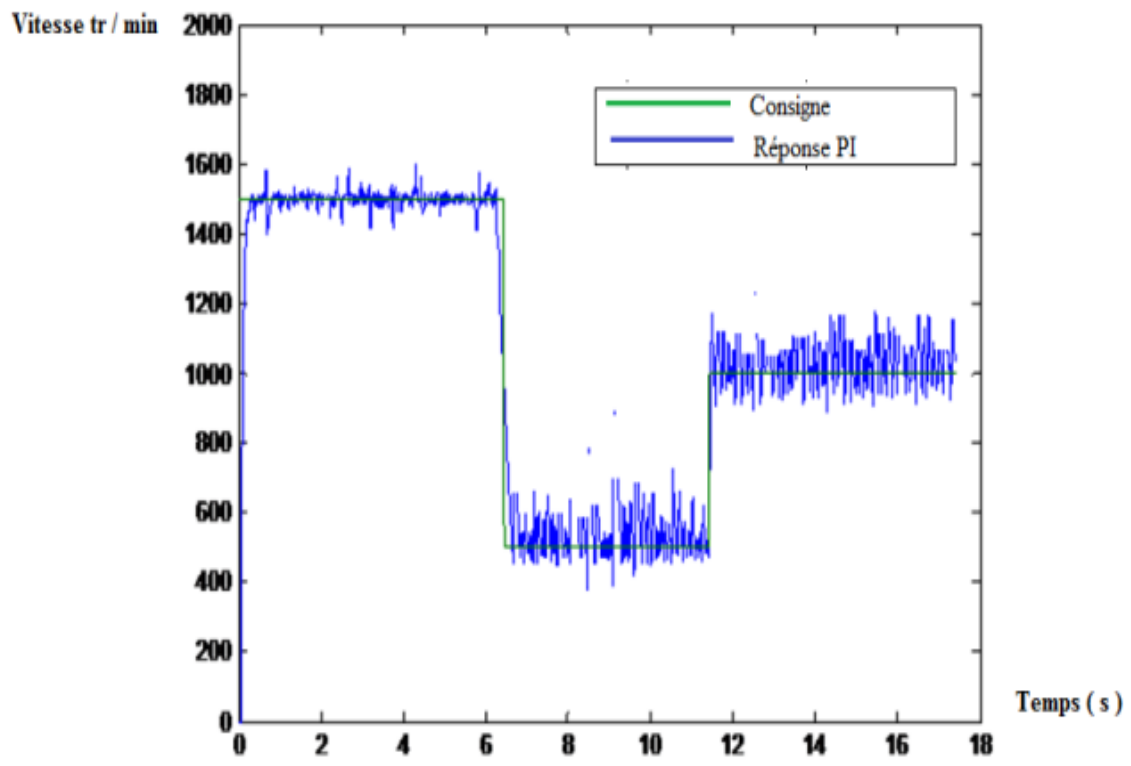

Fig. 13. Behavior of the process with a digital PI (setpoint tracking) 


\section{PRACTICAL REALIZATION}

We will test our system to decrease the effect of the Instant Rotation Center "IRC" in an electric vehicle [4]. Our synoptic diagram is composed of three parts (Fig. 14):

- Control part (PC interface).

- Control circuit.

- Electronic part.

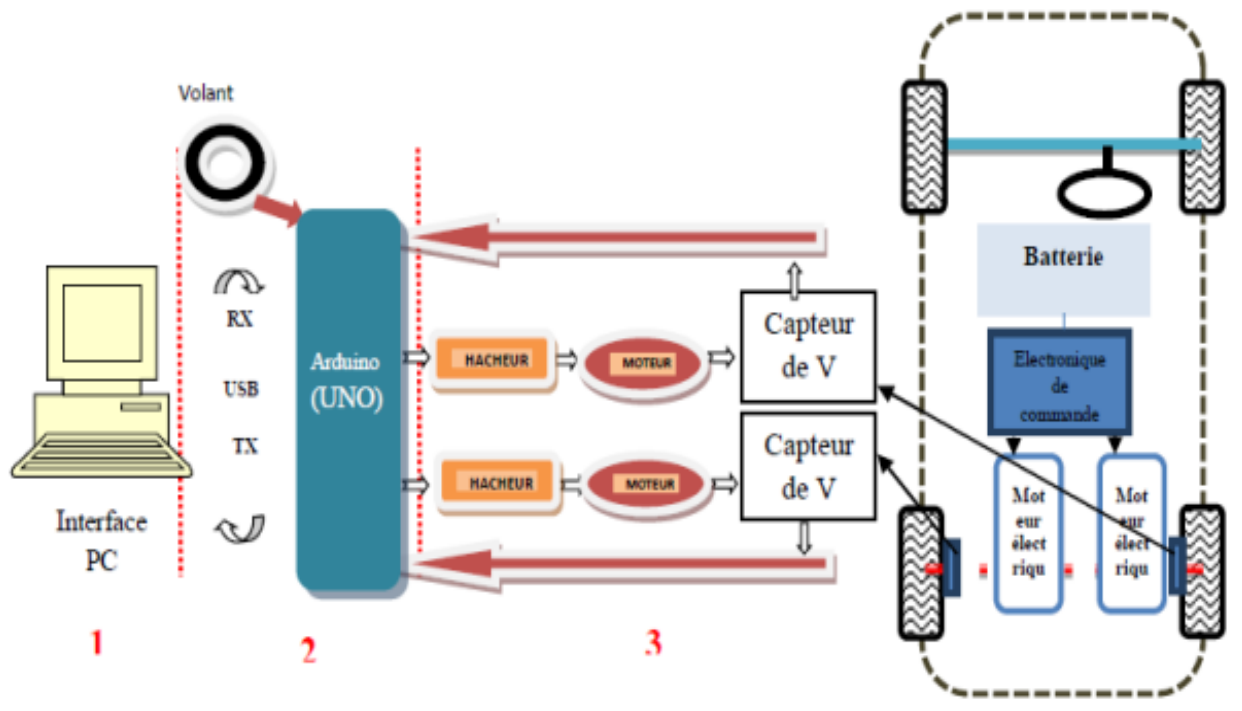

Fig. 14. Synoptic diagram

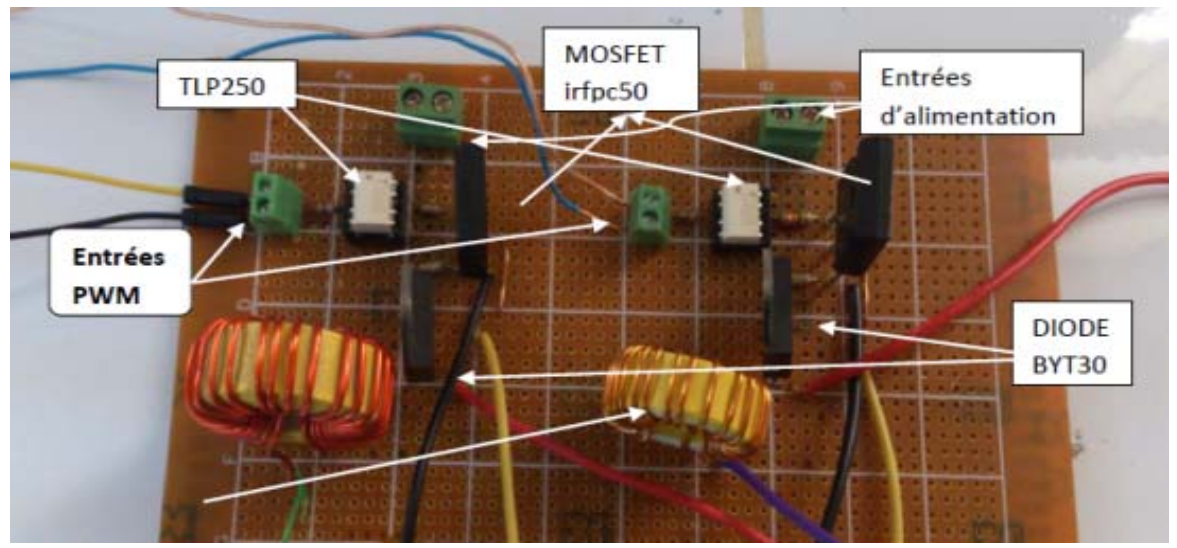

Fig. 15. Realization of the series chopper.

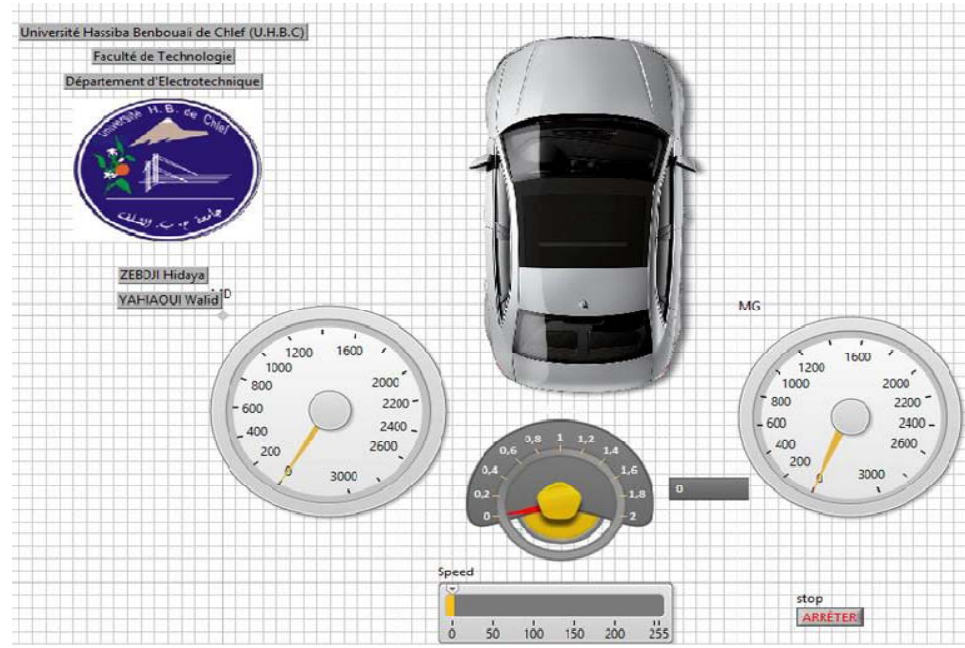

Fig 16. The front panel of our interface 


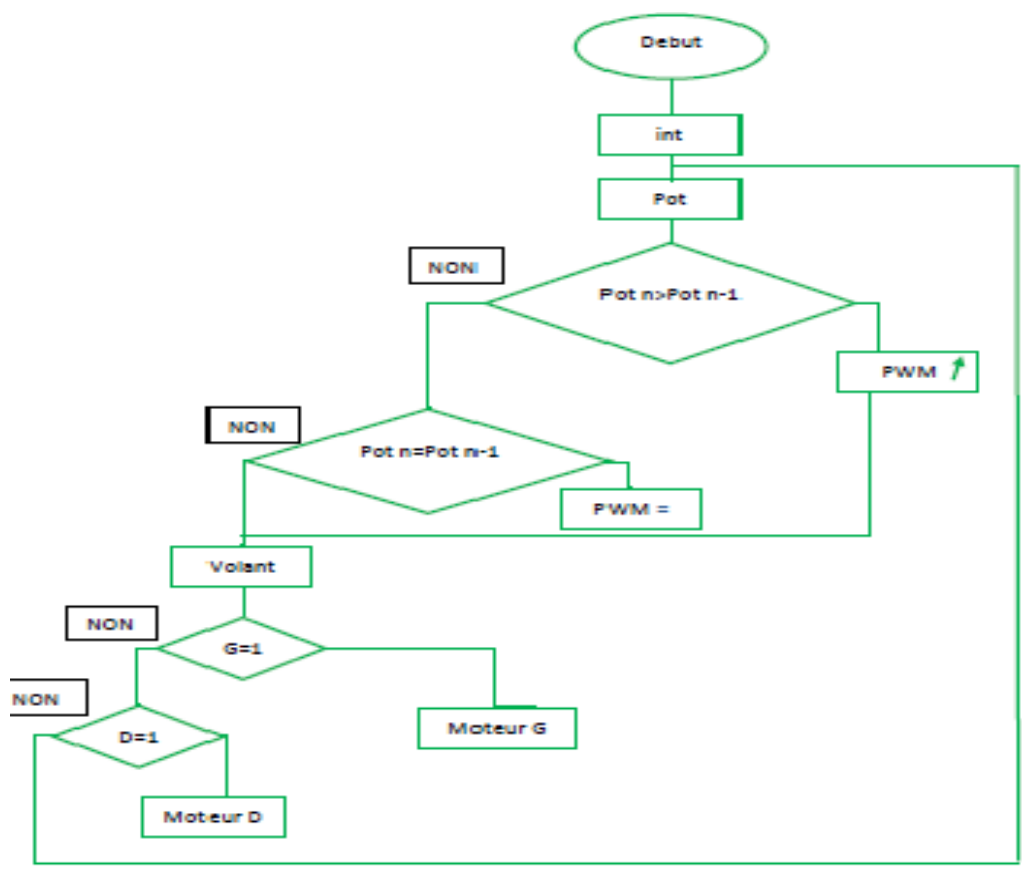

Fig.17. Organizational Chart

XVI. TEST AND RESULT

After the practical realization of our project. We have to do some experimental testing.

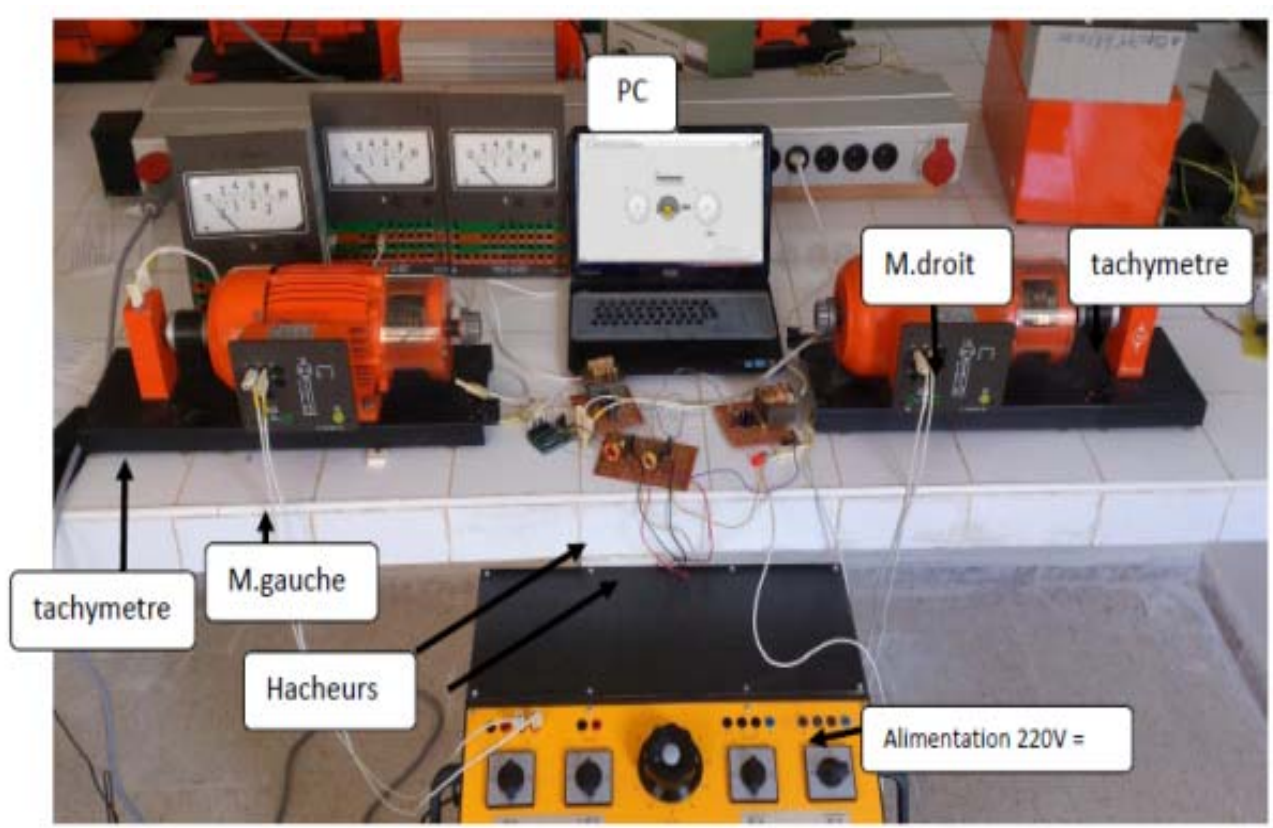

Fig. 18. Assembly of our system

There are three cases:

\section{A. Linear steering:}

When the steering wheel at level 1 no rotation of the steering wheel therefore only has acceleration. 


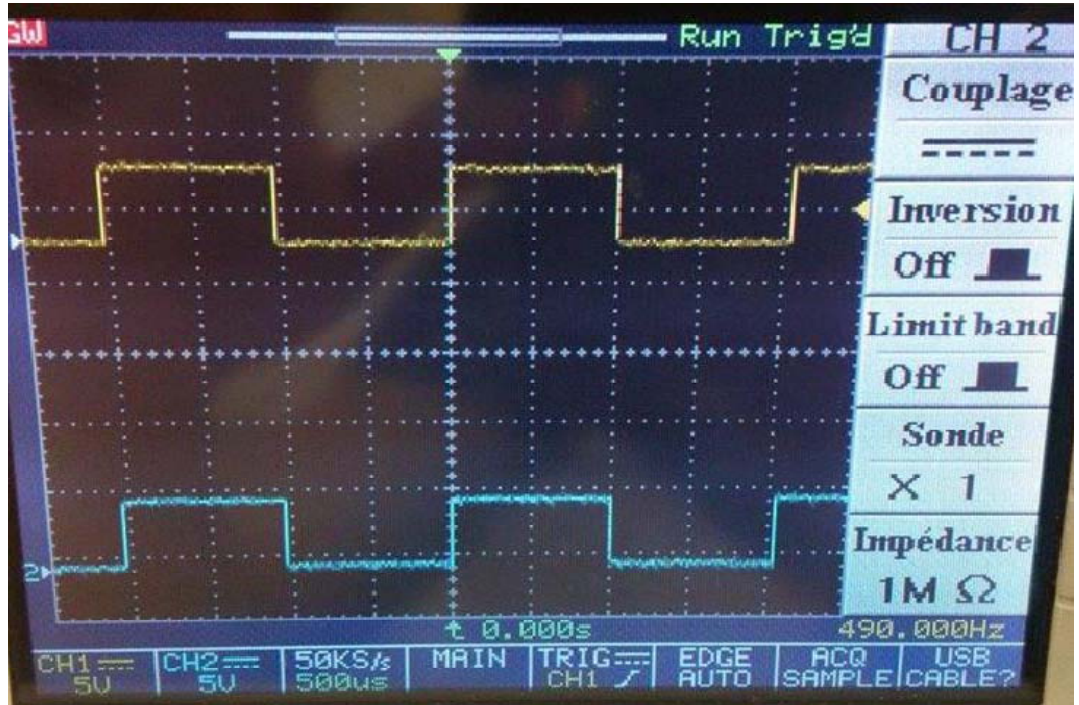

Fig. 19. Steering wheels in position 1.

B. Steering right:

When turning the steering wheel to the right.

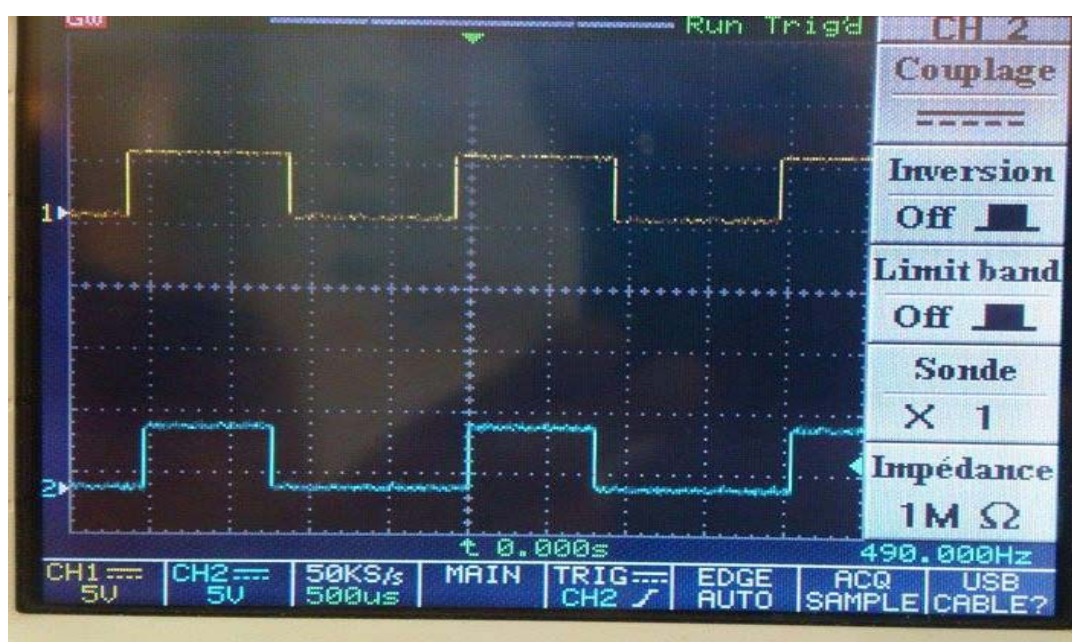

Fig. 20.a: Steering wheel in position [1.1-1.5]

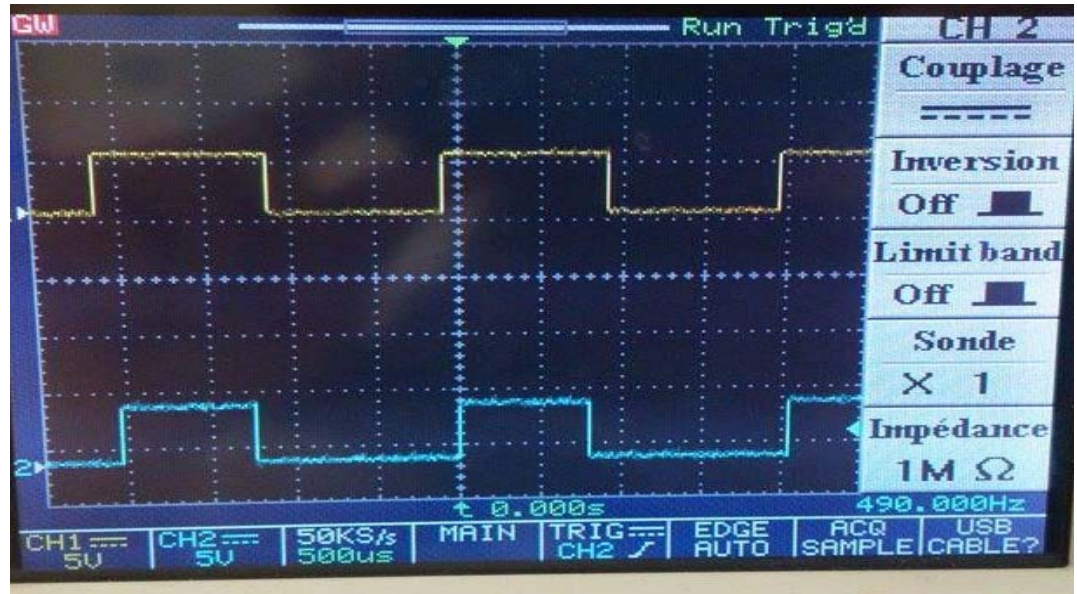

Fig 20.b: Steering wheel in position [1.5-1.8] 


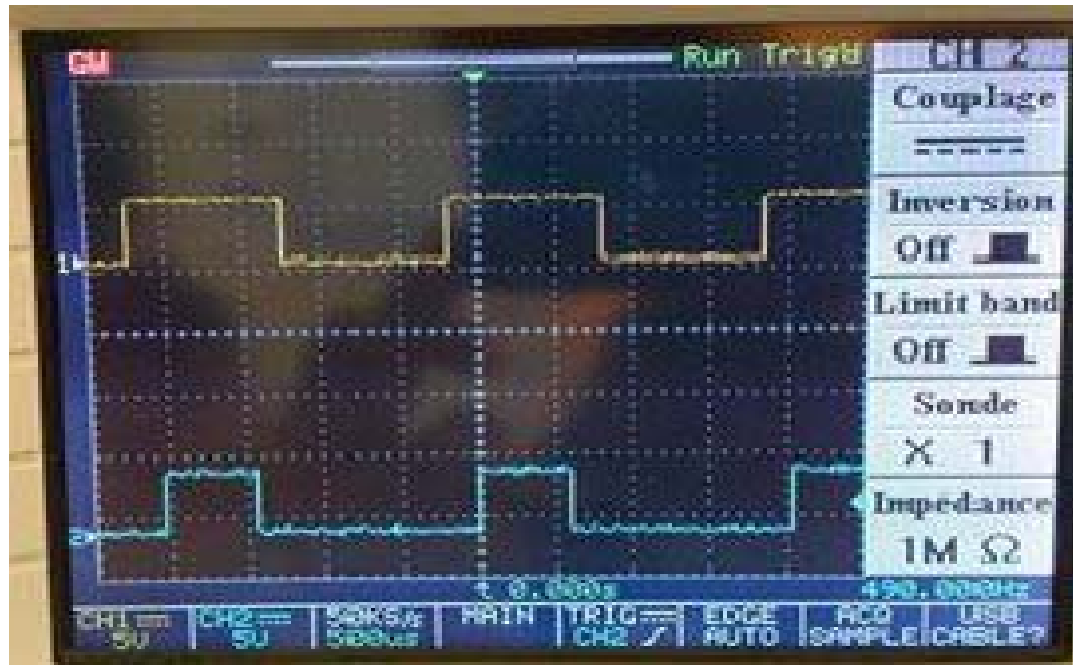

Fig. 20.c: Steering wheel in position greater than 1.8

When turning the steering wheel to the right, the duty cycle (between 1-2) of the signal PWM given to the right engine decreases its speed and the second motor remains constant

C. Left-hand steering:

When turning the steering wheel to the left.

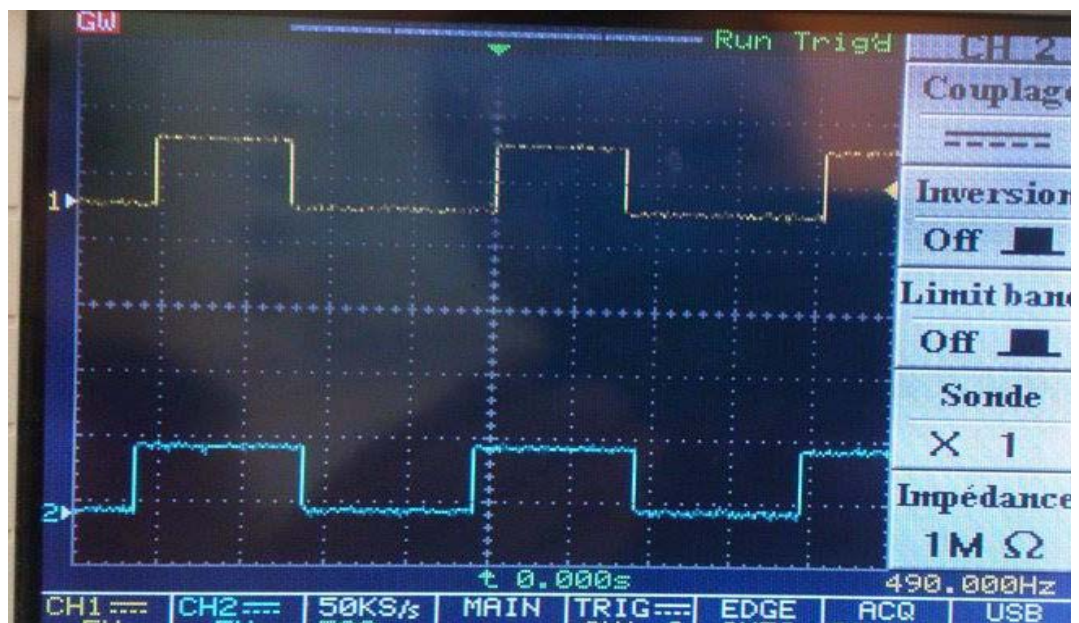

Fig. 21.a: Steering wheel in position [0.9-0.5]

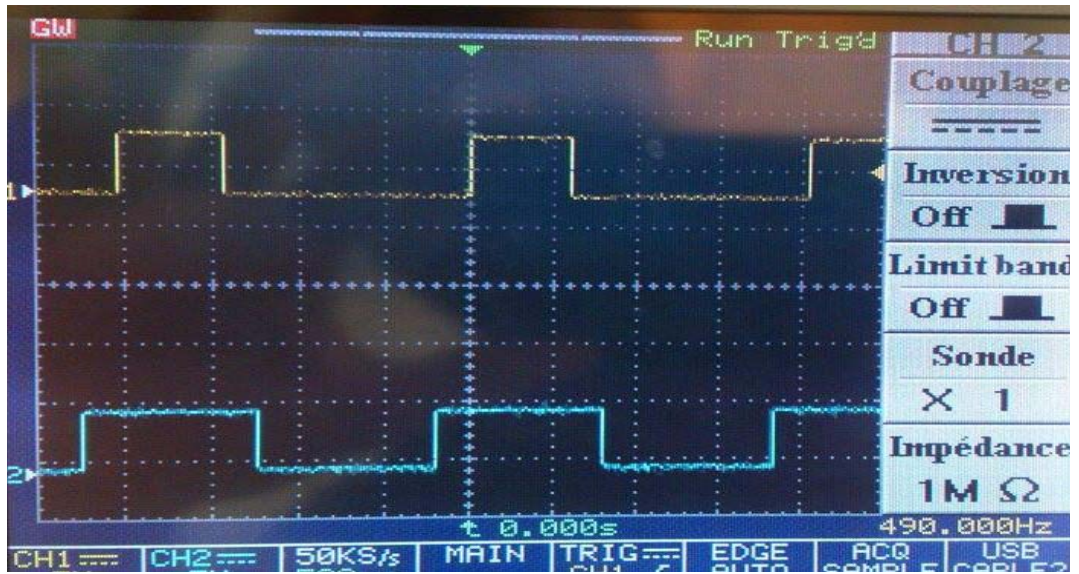

Fig. 21.b: Steering wheel in position [0.5-0.2] 


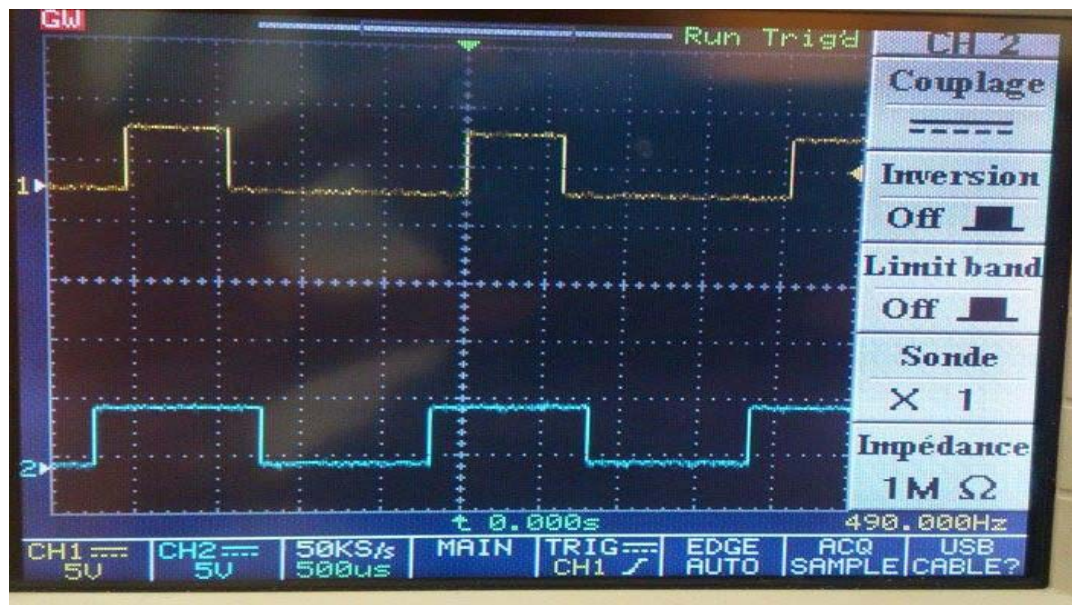

Fig 21.c: Steering wheel in position below 0.2 .

When the steering wheel is turned to the left, the duty cycle (which lies between 1-0) of the PWM signal given to the left engine decreases its speed and the second motor remains constant.

We have shown signals that we have done with our interface. These tests are intended to judge our interface that we have chosen, and obtaining results in the form of graphs on the oscilloscope and on indicators displayed by the speed of the wheels in Labview.

\section{CONCLUSION}

The objective of this work is the study and realization of a system that reduces the effects of the ICR in a vehicle. We used a Labview interface to transmit the signals to the motors (the wheels) and when turning the potentiometer (steering wheel) we notice the variation of the speed of the vehicle with the conditions as we want.

This work allowed us to enrich our knowledge in several fields, especially in the field of electric vehicles and especially on their behaviors and programming in collaboration with Labview.

\section{REFERENCES}

[1] H. Saidi, "Etude et réalisation d'un véhicule solaire (in french)", Master thesis, University of Science and Technology of OranMohamed Boudiaf, Algeria, 2010

[2] Z.B. Ibrahim, M.L. Hossain, I.B. Bugis, J.M. Lazi, N.M. Yaakop, "Comparative Analysis of PWM Techniques for Three Level Diode Clamped Voltage Source Inverter", International Journal of Power Electronics and Drive System (IJPEDS), vol. 5, no. 1, pp. 15-23, 2014.

[3] V.Rajasekar, S. Selvarajan" log gabor filter for image based vehicle verification" International Journal of Applied Engineering Research ISSN 0973-4562 Volume 10, Number 16 (2015) pp.7783-7789.

[4] S. Ramachandran, S. Jaganathan, M. Elakkiya" Eta Algorithm for Vehicle Positioning and Gsm Based Securing Message Through Vehicle to Infrastructure Communication" International Journal of Applied Engineering Research ISSN 0973-4562 Volume 10, Number 16 (2015) pp.8627-8631.

[5] C. Sarath, A. Antony, "Implementation of SVM to improve the performance of a nine level inverter with reduced number of switches", IEEE International Conference on Signal Processing, Informatics, Communication and Energy Systems (SPICES), pp. 1-5, Kozhikode, 19-21 February, 2015. 